\title{
PROBLEMS OF THE FORMATION OF INNOVATION CLUSTERS IN UZBEKISTAN
}

\author{
DILFUZA KURBANOVA \\ Academy of Sciences, Tashkent, Uzbekistan
}

\section{ABSTRACT}

In this paper, we mainly address issues of growth of competitiveness economy in the near future on the basis of innovative development. To that end are examined a questions of formation innovative clusters in economy of Uzbekistan. Considering problem of formation cluster structures of economy of republic and investment of the essential innovative directions, are defined of conceptual directions of strategic investment of innovative directions as structural kernel of NIS.

\section{JEL CLASSIFICATION \& KEYWORDS}

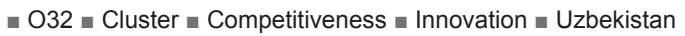

\section{INTRODUCTION}

The matter of choice of competitive industries, i.e. economic activities, makes the problem urgent in addressing the issues of cluster formation, which can really enhance the competitiveness of Uzbek economy in the near future.

In the context of globalization and the effects of the global financial crisis, an interest in exploring the theoretical foundations of a market economy has increased in terms of its cyclical development. Issues of scientific and technological progress are of particular interest, since the basic technologies determine the "technological way" as the country's economy, and in the whole world economy characterized by technological level of the basic technologies used in a specific historical period in certain major industries.

In the context of technological approaches assessing the competitiveness is becoming more important for the present stage of economic development. Currently, the country's competitiveness is determined by its level of technological development, the ability to develop innovatively.

\section{Cluster as a way of innovative development}

It should be noted that one of the promising directions of technological development is the formation of clusters. According to Porter, cluster - is a system organized by a group of economically related firms, suppliers, related industries and institutions that arise in certain regions and countries in order to gain competitive advantage (Porter M.,1998). Based on the current trends in the global economy, the creation of technology (or innovation) clusters has become the actual problem.

As international experience shows, in many industrialized countries, particularly in Japan used the cluster method of forming of a national innovation system (NIS) (Dinikin L. et al., 2004), for example, this approach is fully realized in the automotive industry. In particular corporation JETRO has created and successfully developed 11 clusters (Stimulation of Regional Clusters and International Exchange, 2004). Also formed the territorial scientific innovation clusters.

At the present stage, the model of the innovative development of national economies is being implemented on the basis of the transition from fifth to sixth technological way (Warsawskiy A.E., 2005). In this context, it is expedient for Uzbekistan to implement its own model of transition to an innovative type of economy, which relies on its own intellectual potential and abundant natural raw materials.
Rejecting the "catch-up" model of innovation development, Uzbekistan can take advantage of the investment tools of innovation projects through the development of cluster structure of the NIS.

In this context, "growth points" of competitiveness of the economy of Uzbekistan can be technological (innovation) clusters, which due to its universality, have a high multiplier effect that affects the entire production process: from research, design and engineering products to their production and delivery of ready-made.

Feature of technology clusters is that the specific innovative technologies underlying them are used in a variety of industries, helping to improve the competitiveness of the economy. The advantages of creating technological (innovation) clusters are evident in terms of ensuring and enhancing the competitiveness of national economy in the future, because the most important criterion for cluster formation is the extent of their influence on the efficiency of production as a whole.

Using the world experience in the country, the formation of competitive structure of the NIS on the basis of the development of innovative interdisciplinary industrial (IMPK) and regional clusters (CTI), the main task, which is to generate innovation and commercialization of their results. In this case, investments may be allocated in innovative projects, integrated development of modern science and innovation, investment, financial, industrial and social infrastructure in the form of integrated cluster structures can be developed within the framework of the NIS republics.

\section{Formation innovative clusters}

Given the peculiarities of the Uzbek economy, namely the relatively small area, industry, agriculture, it could be useful to develop cross-sectoral innovation clusters. Formation of regional clusters is possible in the selection of economic regions, for example, the Central Economic Region, including Samarkand, Navoi and Bukhara regions. In this case, the basis for the creation of a cluster should be based on the similarity of comparative advantages possessed by these territorial units of the country.

It should be noted that these types of clusters have targeted focus on the development of innovative and investment activities. On this basis, the main purpose of IMPK is a specialization in macro innovative generation projects, including energy and resource projects to create macro-technologies and the means of production for capital and innovation funds, including products designed for both the domestic and the global market and the accumulation of intellectual human capital. In this case we are talking about basic clusters, which are based on "accelerated development of modern industries and enterprises such as gas processing, petrochemical, chemical industry, energy, automotive, electronics, pharmaceuticals, engineering and, of course, the branch of modern information technologies and systems telecommunications, transport in the near term for digital and widescreen TV.

In addition, special attention should be paid to the further development of production, especially in light industry, textile and food industries, for more in-depth processing of cotton and other agricultural products and raw materials, building 
materials, production of high quality finished products which are in sustainable demand" (Karimov I.A.,2010).

Note that accelerated development of innovative and investment projects are possible on the base of the priority investment areas of breakthrough innovation directions, which consist of a chain of successive actions: "research applied research - financial security and economic incentives for the project - production of new technology, high technology and high-tech products - marketing and promotion of a product to market - sales organization."It should be noted that at each stage of the project it is expected to generate new ideas and inventions - this is, firstly, and secondly, there is the issue of commercialization of new ideas in the life cycles of innovation, which is also possible in the sale of venture capital firms for their further implementation

If we consider the question of formation of the CLC, the main goal is to provide an integrated socio-oriented development of innovative activity in a certain area. This is possible through the development process of generating and commercializing innovative projects at the meso-and microbased integration of knowledge, innovation, investment and finance for large-scale creation of high technology and high-tech competitive products, goods and services both for the domestic market to the outside. In turn, this will provide a comprehensive socio-economic development of the area of human potential and natural resources, i.e. maintenance and protection of natural potential.

Organizational CTI is developed from the basic clusters, i.e. industrial parks, free economic zones and others. Regional orientation of CTI is to invest in innovative projects under long-term programs of integration and diversification of regional innovation systems in the development of innovative economy perspective structure of Uzbekistan, as well as for export diversification by expanding sales in international markets, which have competitive means of production.

\section{Conceptual directions of clusters developments}

Considering the formation of cluster structure of republic's economy and investment vital innovative directions, you should consider this process in the long run. In this case, you should define the conceptual direction of the strategic investment areas of innovation as a structural core of NIS. Thus, in our view, given the economy amid the global financial crisis, it is reasonable:

1. in the period to 2015 (conditional first stage) to develop priority areas of innovation and investment;

2. in 2020 (second phase) to diversify the economic structure formed on the basis of the cluster structure of the NIS in the priority investment IMPK and CTI;

3. in the period from 2025 and in the longer term (third stage) to provide structural and innovative modernization of all sectors of the economy and social sphere.

Thus, in 2025 and further growth of GDP of the republic should be fully ensured by the growth of labor productivity and the share of the contribution of the intensive factors of innovation should be between $60-70 \%$ in GDP growth. Share of investment in innovation reproduction of fixed capital should be maintained at $30-32 \%$ of GDP, while manufacturing will be able to provide not less than $50 \%$ of the gross production of high-tech machinery and equipment, competitive high-tech products, which can be implemented at both the domestic and world markets.

If we analyze the current economic state of the republic, then Uzbekistan has managed to form the macroeconomic conditions for the implementation of the formation and successful development of the national innovation system. www.journals.cz/
GDP in Uzbekistan in 2008 constituted $9.0 \%$ in 2009 - 8,1\%, while in $2010-8,5 \%$, which is to assess the international financial institutions is one of the highest in the world. At the same time, the share of industry in the republic's GDP in 2010 was $24 \%$, transport and communications - $12,4 \%$, services - $49 \%$, agriculture declined $-17,5 \%$. Volumes of investment in the economy rose to the equivalent of 9.7 billion dollars in 2010 , representing $25 \%$ of the GDP of the country (Karimov I.A., 2011).

However, in order to implement innovative investment strategy of the republic's economy it is expedient to conduct appropriate state innovation and investment policies (Abalkin L. et al., 2004), which should become the focus of long-term economic policy.

For the formation of technology (innovation) clusters it is necessary to define the list of critical technologies. In this case, in our opinion, it is also necessary to work out a program of critical innovative technologies with a glance of local resources and industry of the national economy of the country. It is appropriate to say that it is roughly similar to the "Programme of localization in the republic", which defines a list of recommended products for the domestic producers as possible for local conditions and using local resources.

\section{Conclusion}

Therefore, to this end, it is appropriate to identify those innovative technologies on which Uzbekistan in the short term can make a bet in economic development. Solution of this issue can be preparing and adopting an integrated program of scientific and technological progress, which should be developed in line with the innovation and investment policies of the state. In this case, it is important to adhere to the principle of comprehensiveness, as the strategy of innovation and investment policy is the cornerstone of the scientific and technological progress, and they accordingly must be harmoniously complement to each other and interact.

Thus, for the creation of technology clusters the essential prerequisites are required. In this plane, such conditions in Uzbekistan's economy do exist, in particular, there are large national enterprises, which came to world markets. Overall, while there are individual successes in the direction of their transformation into large national corporations, which can ensure the overall competitiveness of the national economy. Formation of technological (innovation) clusters in accordance with the choice of competitive industries requires a new economic development strategy of the republic, in particular, in our opinion; the most appropriate and best direction is resource-innovation development of economy of Uzbekistan.

\section{REFERENCES}

1. Abalkin L. et al. (2004). The Strategic answer of Russia to calls of a new century see., Moscow, 289-290.

2. Dinikin L. \& Ivanova A. (2004). Innovative economy, Moscow, 148-150. 3. Karimov I.A. (2010). Our main task - the further development of the country and increase of well-being of the people, Tashkent, 53.

4. Karimov I.A. (2011). All our aspirations and programs - in the name of the further development of the native land and increase of well-being of the people / The report of President RUz at government session by results of social and economic development of the country in 2010 and to the major priorities for 2011, The truth of East.

5. Porter M. (1998). The Competitive Advantage of Nations, US: Free Press, 207.

6. Stimulation of Regional Clusters and International Exchange. (2004). International Comparative Survey for Vitalization of the Japanese Economy, JETRO, 77-82. Retrieved from http://www.jetro.go.jp/en/reports/ survey/pdf/2004_10_other.pdf

7. Warsawskiy A.E. (2005). Problem and indicators of development of innovative systems. In the book «the Innovative way of development for new Russia», Moscow, 234-235. 